\title{
Selecting an appropriate learning management system in open and distance learning: a strategic approach
}

\author{
Nikhil Kant \\ SOMS, IGNOU, New Delhi, India \\ K.D. Prasad \\ RSD, IGNOU, New Delhi, India, and \\ Kumari Anjali \\ SOS, IGNOU, New Delhi, India
}

Received 20 September 2020

Revised 11 January 2021

21 January 2021

4 February 2021

9 February 2021

11 February 2021

Accepted 16 February 2021

\begin{abstract}
Purpose - This paper aims to derive criteria for a strategic selection of learning management system (LMS) after making an analysis of the feedback data collected from learners and academic counselors in open and distance learning (ODL) to evaluate their perceptions. This analysis hints at the need to implement a learning management system (LMS) in ODL. Selecting an appropriate LMS can prove to be a strategic approach for ODL in achieving self-reliance and competitiveness.

Design/methodology/approach - Research design includes qualitative design intended to discuss the features, advantages and attributes of different popular LMSs and compare them. In addition, the quantitative design (a questionnaire-based online feedback) to analyze the perceptions of the learners and academic counselors in order to know their e-learning needs has also been used. Results have been exhibited in tabular/ graphical formats for easy comprehension and enhanced understanding.

Findings - Findings of the study suggest that availability of plethora of LMSs in the market, which also include open source (OS) LMSs, makes the decision- making as regards selection of an appropriate LMS strategically crucial requiring adequate consideration of every aspect such as cost, quality, usage, capacity, budget and most importantly priorities and objectives.

Research limitations/implications - This study will help educational administrators and decision-makers in ODL for building a quality civilized life and empowered society by removing the constraints related to financial problems, disabilities, time, geographical conditions and many others in bringing education to the doorstep of every willing learner. The technical details of LMS, however, were intentionally kept simplified to achieve the objective and provide easy comprehensibility for the reader with little technical background, which might be a limitation of this study.

Originality/value - This study highlights that ODL has tasted success with optimum exploitation of different technological advancements in its transformational expedition from conventional learning to innovative e-learning and to the newest adaptive e-learning system. The huge potential of LMS, in providing learners and educators in ODL with an effective web-based learning system incorporating almost all the academic activities, has attracted organizations for using it not only for imparting education to learners but also for providing appropriate trainings to their human resources.
\end{abstract}

Keywords Learning management system (LMS), Open and distance learning (ODL), Open source (OS), Sustainable development goals (SDGs), Strategic approach, Technological advancements

Paper type Research paper

(C) Nikhil Kant, K.D. Prasad and Kumari Anjali. Published in the Asian Association of Open Universities Journal. Published by Emerald Publishing Limited. This article is published under the Creative Commons Attribution (CC BY 4.0) licence. Anyone may reproduce, distribute, translate and create derivative works of this article (for both commercial and non-commercial purposes), subject to full attribution to the original publication and authors. The full terms of this licence may be seen at http:// creativecommons.org/licences/by/4.0/legalcode

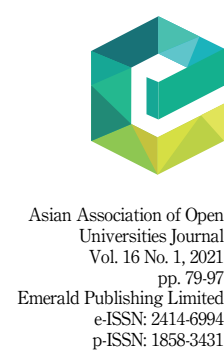

DOI 10.1108/A p-ISSN: 1858-3431 
AAOUJ

16,1

80

\section{Introduction}

Advancements and innovations in technology have affected different fields of our daily life including innovative methods adopted for education and trainings. Ramadhani et al. (2019) argue that adoption of appropriate technological advancements is found to be immensely useful in making learning and teaching more dynamic in education. These arguments are further supported by Abdurrahman et al. (2019) that it not only affects the relationship between educational instructors and learners but also the value of the education system arising from the improvised learning process. Having encountered numerous challenges and barriers, learners including lifelong learners have resorted to open and distance learning (ODL), which is known to have successfully harnessed technological advancements for providing them with enabling learning environments due to enhanced interactivity offering newer opportunities of education for the learners who have been facing various constraints in the conventional system of learning (Kant and Anjali, 2020; Nayak et al., 2020). In these situations, learning management system (LMS), by virtue of its huge perceived latent potentialities, has offered itself to be exploited appropriately for the satisfaction of the educational needs of learners and instructors both.

An LMS contains an effective web-based learning system of sharing study materials, making announcements, conducting evaluation and assessments, generating results, communicating interactively in synchronous and asynchronous ways amongst various other academic activities. There has been greater emphasis of implementing an LMS more particularly in developing countries in recent times, posit Bervell and Umar (2017), where majority of the educational institutions in general and higher educational institutions in particular have employed LMS to enhance delivery of education as the mediating technological platform between the educational instructors and learners bridging the gap between them in an ODL system (Naveh et al., 2012). LMS, thus, is being used comprehensively by advanced educational institutions in imparting education to learners and also providing trainings to academic as well as administrative human resources (Alameen and Dhupia, 2019).

In one such developing country India, the erstwhile Distance Education Council (now Distance Education Bureau under the UGC in India,) had sensed the future needs a decade ago. It had started to make efforts to improve the quality of ODL programmes through an LMS using a technological platform for facilitating and supplementing educational programmes offered by ODL including professional and vocational programmes in order to increase skills and competencies for improved prospects of employability. Emphasis was on implementing a LMS integrating the essential teaching elements of class sessions, learning materials, virtual lab and assessment/assignment in addition to the provisions of a framework to translate the contents into other major languages of India and provisions of adding contents to the sessions by teaching staff (IGNOU, 2011).

Given that different LMSs have different set of advantages and disadvantages, selection of an appropriate LMS is of strategic significance for institutions. This paper, taking a cue from an analysis of the feedback data collected from learners and academic counselors in ODL to evaluate their perceptions, aims to derive the criteria for strategic selection of LMS to implement it in ODL. This paper will facilitate the decision-making for implementing an LMS in ODL as selecting an appropriate LMS can prove to be a strategic approach for ODL in achieving competitiveness. To that end, the next section informs in brief the changing landscapes of ODL contextualizing an Indian perspective. The consequent sections provide information about the materials and methods employed in this study and present an abridged account of the perceptions of ODL stakeholders, namely learners and academic counselors for an enhanced understanding of the background of this study. Next is a section providing relevant information related to an LMS for an enhanced understanding. Finally, there is a section elaborating the selection of LMS in ODL as a strategic approach before culminating 
into the conclusions section. The findings will be useful for future researchers in getting suitable research directions and also for the educational administrators and decision-makers engaged in the field of ODL system for building a quality civilized life and empowered society by removing the constraints related to financial problems, disabilities, time, geographical conditions and many others in bringing education to the doorstep of every willing learner more particularly in developing countries.

\section{ODL: the changing landscape}

COL (2020) highlights ODL is an educational innovation which has flourished immensely in previous several decades with the support of robust principles of pedagogy and immense power of technological innovations. McQuaide (2009) states it has successfully been combating constraints related to access, presenting itself as a viable alternative of capacity building. Ural (2007) argues that ODL has emerged as a possible alternative of traditional system of learning, which has been struggling with plethora of problems in maintaining quality primarily due to overcrowded classrooms. Brown (2006) highlights that last few decades have witnessed ODL emerging phenomenally in the form of an effective mode of learning, inducing the shift in learning paradigm from "Teaching to Learning Facilitation to Facilitated and Supported Enquiry". Across this expedition starting from correspondence to the new and innovative forms, ODL has harnessed optimally the technological advancements to live up to the dynamically changing learning needs.

Leveraging the huge potential of ensuring presence of teachers and learners at the same time and space, ODL has been successful in maintaining the continuance of teaching learning process during any adverse circumstances such as floods, conflict, fires or any such event. Its unparalleled contributions have been duly acknowledged and applauded during the occurrence of coronavirus disease 2019 (COVID-19) pandemic when the ODL institutions remained functional even though other institutions remained closed (COL, 2020). The unique attributes of ODL have helped it to expand exponentially and attract learners greatly using the advantages of technological innovations to harness the benefits of globalization in the field of higher education, which also have exposed it to several accreditations, such as collaborations, quality, digital divide, equity and human rights related challenges requiring proactive approaches from ODL to address them (Jung, 2005).

UNESCO (2002) reports that ODL, as a representative of the educational process with greater usage of teaching and communication, seeks support from the artificial print/ electronic medium to bridge the gaps of time and space between learners and teachers. It considers technological innovations vital to enhance its effectiveness, underpinned by the development of certain role-specific competencies helpful in becoming a better competitor than conventional mode of learning. Brenner (2007) and Kant (2020) lay emphasis on the transforming capability of the innovative technologies as regards the instructional delivery mechanism in ODL between learners and instructors in imparting theoretical as well as practical learning. As Tait (2018) and Nayak et al. (2020) argue, globalization, in the meantime, requires ODL institutions to be ready for competition not only from local but also overseas and institutions to embrace advanced technology for making the most of the strategic advantages of technological developments in order to enhance access and flexibility.

The countries in the Asia-Pacific region, having huge actively enrolled students in a number of mega universities, have been making efforts to harness the potential of ODL (Jung, 2005) in their bid to attain sustainable development (Siaciwena and Lubinda, 2008). COL (2020) demonstrates a roadmap for harnessing the capacity of ODL in developing countries (highlighting its huge contributions to the education sector as regards increasing access and quality, improving support for inclusion, reducing costs and carbon footprint) such as India. India has a much less Gross Enrolment Ratio (GER) in higher education of only $24.5 \%$ in the 
AAOUJ 16,1

\section{2}

age group of 18-23 years while some of the developed countries have reached $90 \%$ or more. However, ODL in India currently has remarkable $12 \%$ of the total enrollments in higher education and promises to contribute significantly to the GER and education to the disadvantaged learners (MHRD, 2016).

While COL (2020) underscores the importance of ODL mentioning that it is serving the needs of more than 4.4 million learners in the Commonwealth, the arguments of Wolcott (2003) also highlight the support that developing countries like India have secured from the growth of ODL for taking higher education to the farthest parts of the country with the optimum use of technology in providing better learning experience with higher flexibility, interactivity and self-reliance. COL (2020) lays emphasis on the urgent need to promote and implement technology-driven learning policies and strategies to deploy affordable technology giving due attention to the constraint of access to computers and Internet connectivity, which are the biggest challenges in the way of ensuring last mile access. COL (2020), further, underscores the urgent need to develop blended learning environments in line with the learners' needs and to embrace a suitable online learning system to achieve expected learning outcomes.

\section{Materials and method}

In this study, a qualitative design has been applied to review the extant literature for the purpose of discussing the features, advantages and attributes of different popular LMSs and for comparing them, so that the decision-making for implementing an LMS in ODL could be facilitated to ensure enabling an e-learning environment through selection of the best-suited LMS, as a strategic approach to achieve enhanced competitiveness. A quantitative design has also been applied for analyzing the data collected by IGNOU (Indira Gandhi National Open University) through a questionnaire-based online feedback using SPSS 21 for the statistical tests and descriptive analysis to analyze the perceptions of its learners $(n=51,801)$ and its academic counselors $(n=3,284)$.

\section{Understanding the background through analyzing perceptions of ODL stakeholders}

In India, the IGNOU as an apex ODL institution has continuously been extending guidance to other institutions with similar objectives by its leadership in optimally utilizing technological advancements. It has improved satisfaction of learners by appropriately realizing that ODL depends heavily on the learner-centric flexible approach for its recognition. This realization has provided the IGNOU with the leadership position among ODL institutions (IGNOU, 2020).

This study used the data collected through two separate questionnaire-based online feedbacks collected by the IGNOU to evaluate the attitude of its learners $(n=51,801)$ toward the usefulness of the provision of self learning material (SLM) in electronic media for mastering the content and of its academic counselors $(n=3,284)$ toward the keenness of the learners to use the e-SLM for studying the course. The coefficient reliability of the questionnaire disseminated among learners was checked using Cronbach $\alpha$, the value of which was substantially high (0.90). It hinted at the adequate reliability of the questionnaire (Nunnally, 1978). The initial questions were related to the general profile of the learners followed by the question to know their attitude toward the usability of the provision of SLM in electronic media for mastering the content. The descriptive statistics of the general profile of the respondent learners in terms of gender, employment status, category and age groups (in years) are presented in Figure 1.

Majority of the learners (49.17\%: agree, and $14.27 \%$ : strongly agree totaling $63.44 \%$ ) had favorable attitude toward the usability of the provision of SLM in electronic media for 

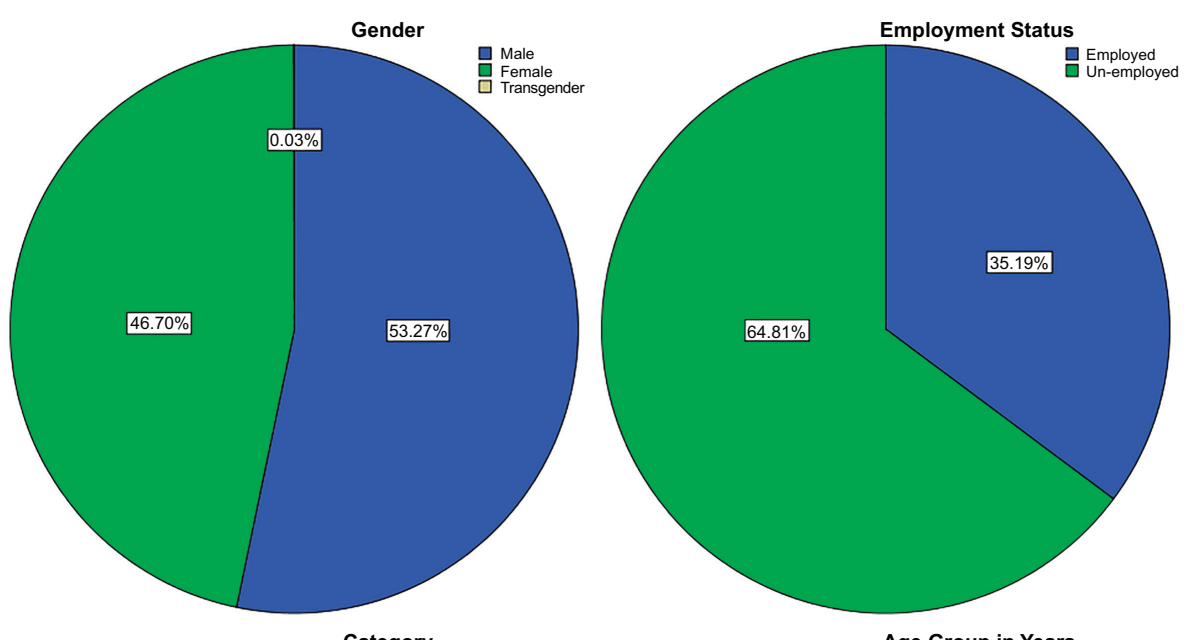

\section{Learning management system in ODL}
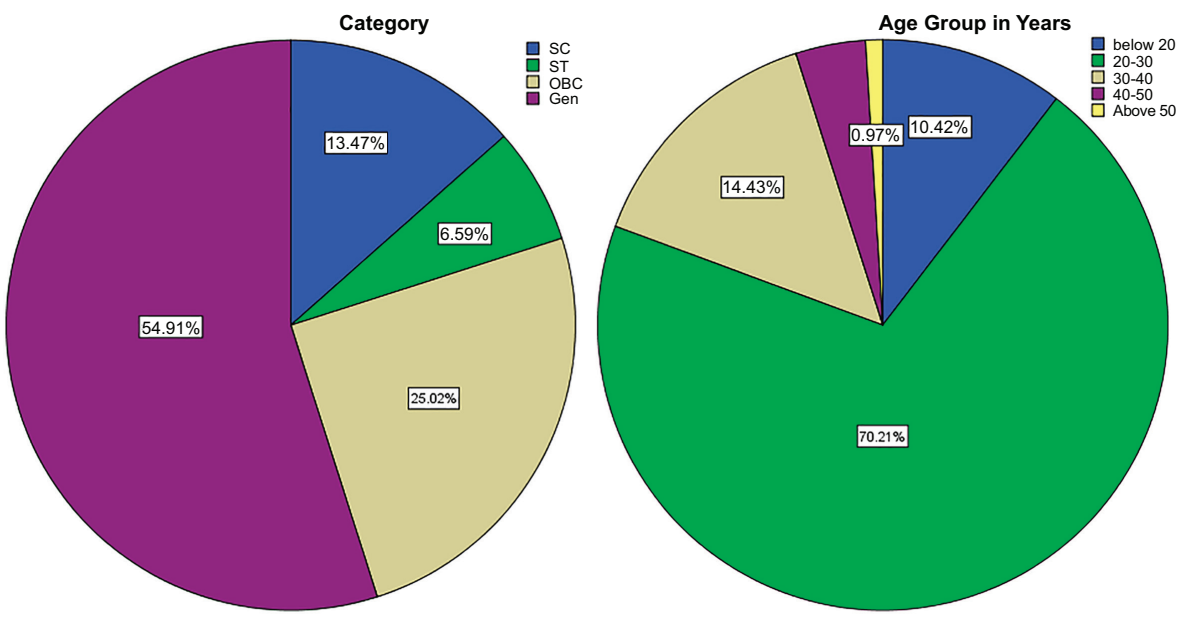

Figure 1. General profile of the respondent (learners)

mastering the content whereas $25.86 \%$ were neutral. However, there were only few learners $(8.68 \%$ : disagree, and $2.02 \%$ : strongly disagree totaling $10.70 \%)$ who had negative attitude. The evaluation of the learners' responses suggests that the usability of the provision of SLM in electronic media for mastering the content was adequate (Table 1 and Figure 2).

\section{Mean}

Median

Mode

Std. deviation

Variance

Skewness

Kurtosis

Minimum

Maximum
4

0.899

0.808

$-0.640$

0.322

1

5
Table 1.

Descriptive statistics regarding usability of the provision of SLM in electronic media for mastering the content 


\section{AAOUJ 16,1}

\section{4}

Figure 2.

Usability of the provision of SLM in electronic media for mastering the content

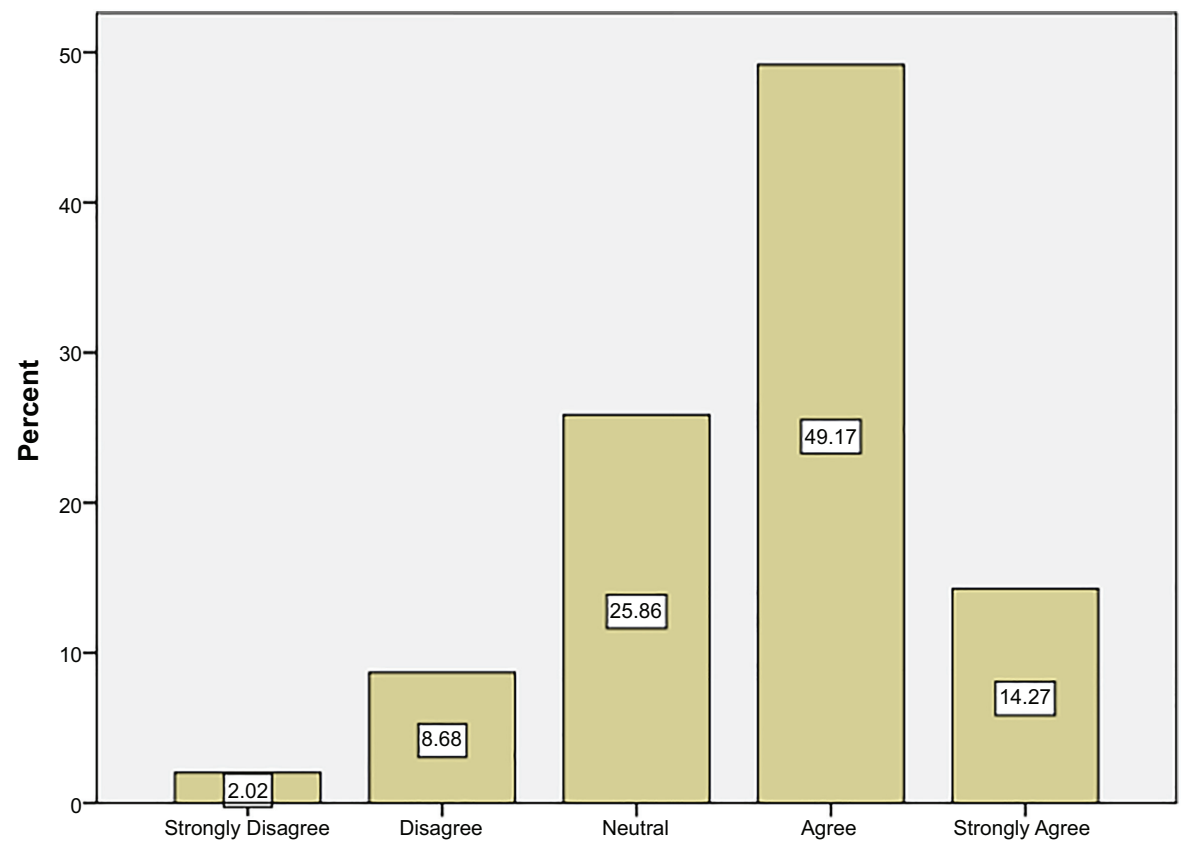

Provision of SLM in electronic media is useful for mastering the content

The coefficient reliability of the second questionnaire related to the academic counselors ' feedback was checked using Cronbach $\alpha$, in which the value was substantially high (0.84). It too hinted at the adequate reliability of the questionnaire (Nunnally, 1978). The initial questions were related to the general profile of the academic counselors followed by the question to know their attitude whether the learners are keen to use the e-SLM for studying the course. The descriptive statistics of the general profile of the respondent the academic counselors in terms of gender, age groups (in years), category, total experience as academic counselor in the IGNOU (number of years) and whether they have attended the orientation programmes conducted by the IGNOU are presented in Figure 3.

Majority of the academic counselors (51.98\%: agree, and $20.04 \%$ : strongly agree totaling $72.02 \%$ ) had favorable attitude that the learners are keen to use the e-SLM for studying the course whereas $19.31 \%$ were neutral. However, there were few academic counselors $(7.98 \%$ : disagree, and $0.70 \%$ : strongly disagree totaling $8.68 \%$ ) who had negative attitude. The evaluation of the academic counselors' responses adequately suggests that the learners are keen to use the e-SLM for studying the course (Table 2 and Figure 4).

The analysis of the feedback data received from learners and academic counselors helps in concluding that not only the learners but also the educators have favorable opinion for the e-learning. Since the Internet-based technological advancements, LMS has evolved as one of the most common e-learning technological platforms transforming the education delivery in ODL (Mohamedbhai, 2011) and adoption of an appropriate e-learning system invariably constituting an LMS would enhance the usability of the provision of SLM in electronic media in the teaching learning process in ODL. Their attitudes hint at the possibility that using an LMS would enhance their interest in the study reducing the challenges associated with a 

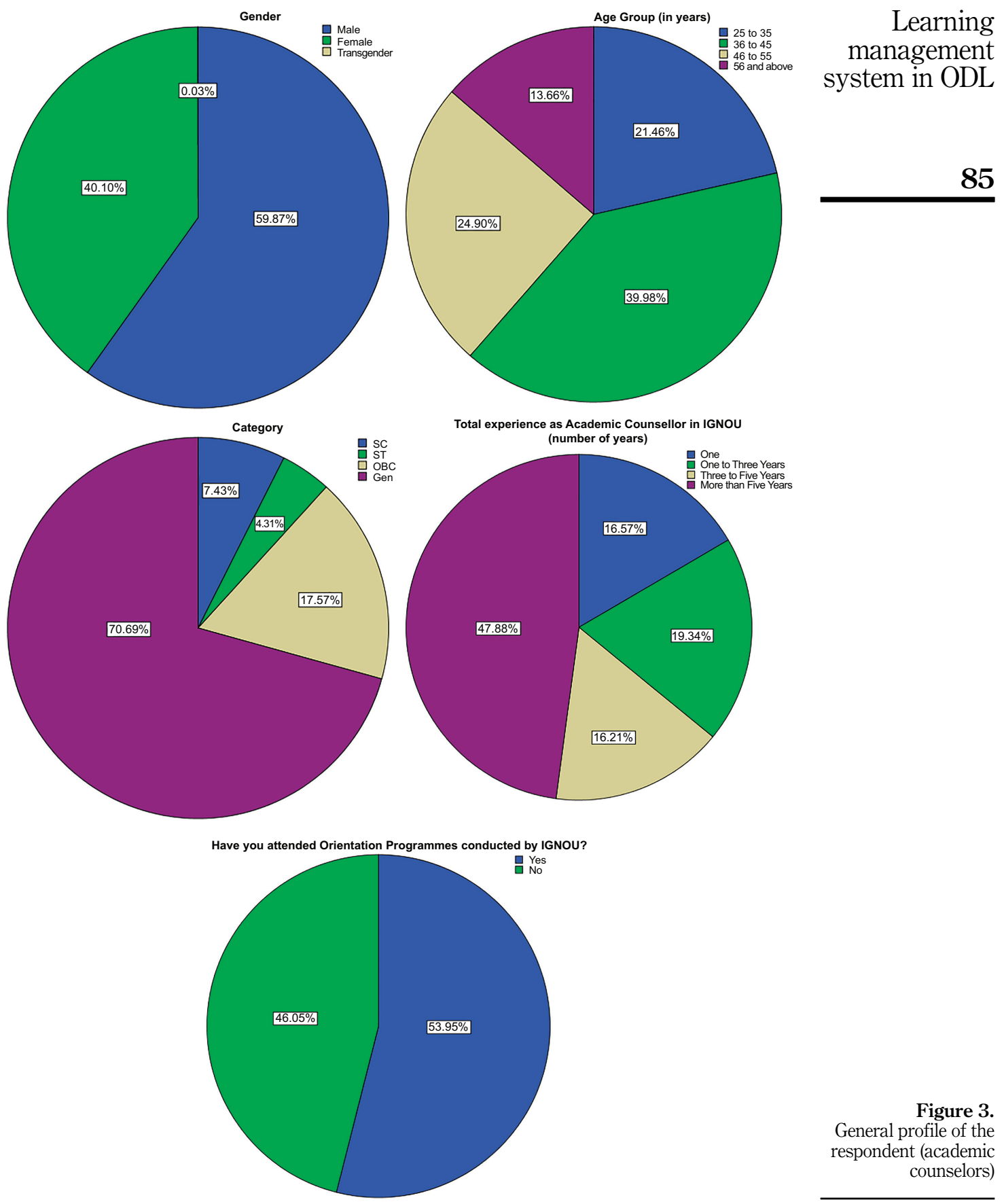

Figure 3.

General profile of the respondent (academic counselors) 
AAOUJ 16,1

\section{6}

monotonous self-learning mechanism making learning more interactive and meaningful mentoring their individualized learning based on the individual's learning style.

\section{Learning management system (LMS)}

The evolution of ODL is partly attributed to the technological advancements, and their contributions are reflected in different generations of delivery of education in an ODL system (Bervell and Arkorful, 2020). Education has continuously been undergoing fundamental transformation keeping pace with the dynamic technological advancements. The continuous transformations have increased variety in the learners and their needs with higher demand for greater flexibility, interactivity and ease in learning anytime anywhere (Nayak et al., 2020). It is notable that the advent of Internet has offered plethora of teaching learning tools and applications to be used at different stages of teaching enhancing the teaching- learning

Table 2.

Descriptive statistics regarding keenness of the learners to use the e-SLM for studying the course

\begin{tabular}{lc}
\hline Mean & 3.83 \\
Median & 4.00 \\
Mode & 4 \\
Std. deviation & 0.864 \\
Variance & 0.746 \\
Skewness & -0.664 \\
Kurtosis & 0.251 \\
Minimum & 1 \\
Maximum & 5 \\
\hline
\end{tabular}

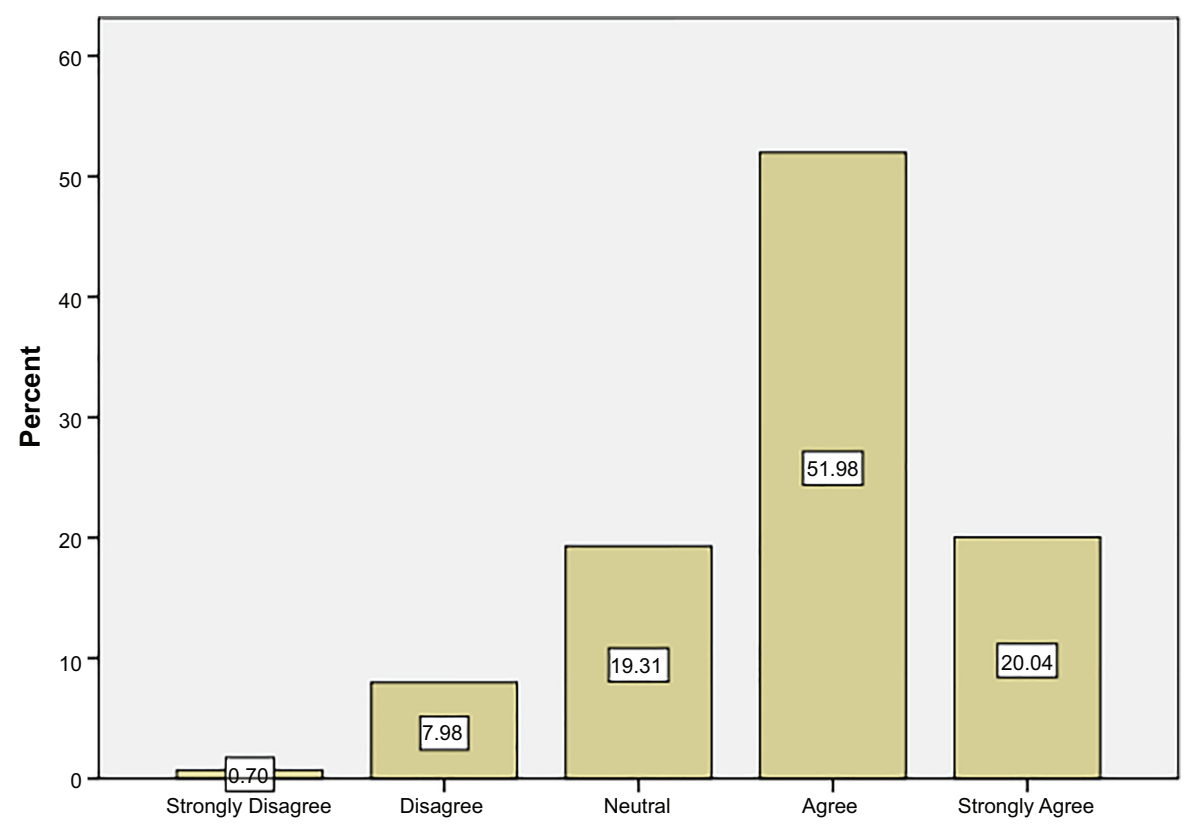

The learners are keen to use the e-SLM for studying the course
Figure 4.

Keenness of the learners to use the e-SLM for studying the course 
process more effective and efficient (Cavus, 2015). Aoki (2012) argues that the current era of ODL is its fifth generation, which is based on the intelligent flexible learning model using the interactivity of Internet, having migrated from the third generation, which used information and communication technology (ICT) effectively for the first time to incorporate interactivity in distance learning to be accepted as an era of open and distance learning, and forth generation which used Internet for online delivery of content.

Introduction and continuous increase in the usage of LMS in the new century have transformed the delivery mechanism of education not only in an ODL system but also the conventional face-to-face based distance education, which have leveraged the mediating technological capabilities of LMS in the relations of educational instructors and learners (Bervell and Arkorful, 2020). Mohamedbhai (2011) too argues that with the advancements in the Internet-based technologies, LMS has evolved as one of the most common technological platforms, which have transformed the education delivery in distance education system.

Lonn and Teasley (2009) define LMS as a web-based system, which facilitates learners and instructors in sharing learning materials and assignments, and communicating online. Its quality and scales can be assessed by expenditure incurred on software, its update and support mechanism. The LMS contains facilitating mechanisms for registration, course/ participants statistics, scheduling, assessments, examinations, grades, synchronous and asynchronous communications and materials, such as interactive applications, contents, documents, papers, audio and video files, supporting teaching- learning process and further enhancing their sustainability and reusability.

Karagöz et al. (2017) emphasize the need for its user-friendliness, and Chao and Chen (2009) enumerate quality of e-learning platform, materials, synchronous learning, learning records and self-learning as the primary selection criteria of LMS. Further, Chao and Chen (2009) underscore the usability of e-learning, which invariably constitutes an LMS, in ODL in increasing the multiple advantages and alternative learning opportunities for learners in getting education without facing the constraint of space and time more particularly in an asynchronous manner at the same time, also saving costs for ODL institutions. Further, Dzandu and Tang (2015) remind that these learners also include workers and learners in remote areas who, despite willing to get education, do not have access to a conventional classroom learning system, thanks to plethora of constraints. Bervell and Arkorful (2020) find that several factors and facilitating conditions such as voluntariness of use and actual use behavior are abundantly showcased in the contemporary studies as enablers for LMS usage in real world. Karagöz et al. (2017) and Shee and Wang (2008) highlight its emergence as a new means of facilitating learning which has been encouraged, not only academia but also industry, for making commensurate investments in its adoption.

The LMS preserves the logs of the users such as system administrators, course coordinators, instructors, learners and guests and of system also (Karagöz et al., 2017). Cavus (2015), Fojtik (2015) and Lonn and Teasley (2009) argue in favor of preparation of suitable learning materials for ODL learners using technology to eliminate the misconception among new or prospective learners that ODL is harder than conventional face-to-face learning (Fojtik, 2015). Karagöz et al. (2017) argue in favor of the greater usability of LMS as a learning tool in ODL underscoring its increased use in a number of universities globally. Muñoz et al. (2015) too hint at its huge potentialities in introducing advanced features to improve teaching learning experience, contributing finally toward improvised academic outcomes.

The LMS can broadly be categorized into two groups, i.e. free open source (OS) LMS and commercial proprietary LMS, put forth by Karagöz et al. (2017). It is notable that Chao and Chen (2009) in their study have highlighted the significance of license costs, learning flexibility, security and market share as the main factors for decision-making as regards selection of LMS. Here, Karagöz et al. (2017) consider LMS as the solution of plethora of problems related to ODL, and OS which, as Cavus and Zabadi (2014) inform, is the software 
AAOUJ

16,1 source code readily available to any user free of cost for extension and modification as per needs; therefore, OS LMS is not similar to the priced commercial proprietary LMS being sold in the market. Since OS LMSs are available in the market with different strengths and weaknesses (Capterra, 2020), it becomes strategically significant to be adequately informed about them.

\section{Strategic selection of appropriate LMS in ODL}

Discussions so far lay emphasis on the need to ensure inclusive and sustainable development, leveraging the greater access, equality, quality and expansion related potentialities of an ODL system. Bordoloi (2018) argues that higher ease and comfort of ODL institutions with technological developments can strengthen higher education system in developing countries by improving capability of providing learners with affordable education at their doorstep without compromising quality. The emphasis of Noorani (2014) is on the urgent requirement for every organization to keep itself on continuous lookout for newer tools, services and approaches for the purpose of securing competitiveness. Technological innovations such as LMS possess immense disrupting potentialities with lasting effects on ODL. Kant (2019) emphasizes that, with the increased competition in the ODL environment, instructors in ODL must possess fundamental characteristics such as possession of fundamental technological skills and ease in using tech-tools and pedagogical practices in line with greater meaningful learner-centered learning, in addition to subject knowledge. Kant (2019) also emphasizes the need for them to make continuous efforts to enhance capabilities of combining tangible and intangible resources, so that they could remain competitive and useful in an educational arena witnessing continuously increasing institutions with similar objectives in a liberalized, privatized and globalized world.

Using a commercial LMS requires huge investments for an organization (Alameen and Dhupia, 2019) more particularly in the ODL system, which has already incurred huge expenditure on fixed assets (Kant, 2020). Selection of such an OS LMS which has potentials to offer user-friendly tool integration by virtue of possessing similar features of a commercial LMS can be helpful for an institution in saving expenditure on e-learning implementation. These discussions on different OS LMSs can help decision-makers in ODL in implementing an LMS in order to embrace adaptive e-learning transitioning from conventional e-learning. The analysis of the feedback of the learners and academic counselors also supports this. Alameen and Dhupia (2019), highlighting that license cost is more important than other factors, consider selection of the appropriate OS LMS with the best tools is a strategically important decision for its successful implementation. Focusing on the significant criteria as regards their usability and features, the outcome of an attempt to search relevant OS LMSs is presented in Table 3.

Above comparison of OS LMSs, based on significant criteria with respect to their relevant usability and features in ODL, provides a fair idea for selection of an appropriate LMS. The decision-makers in ODL can make the best selection based on the significant features, learning processes and characteristics of the LMS tools depending upon their objectives and priorities. The other relevant details, which might be useful for them, are also provided in Table 4.

While "Make My LMS" is the only LMS located in India and the latest among them, it is notable that some of these OS LMSs, for e.g. "Moodle" the oldest among all of them, have been adopted by multiple institutions including universities. As Alameen and Dhupia (2019) report, they have been researched upon substantially, have offered a developer's experience sharing forum in order to address associated problems by providing ready solutions and also have used innovations profusely providing thereby sufficient guidance to the new project developers, Alameen and Dhupia (2019) further inform that suitable OS LMSs offer variety of 


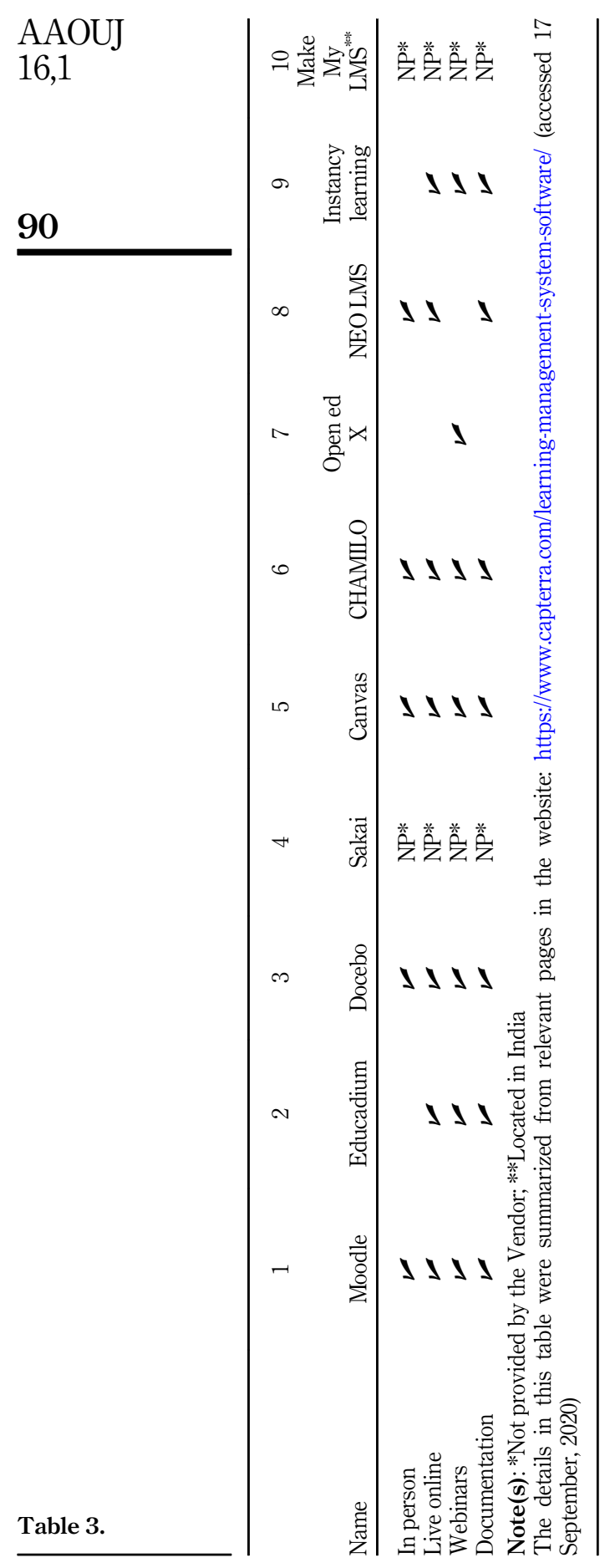




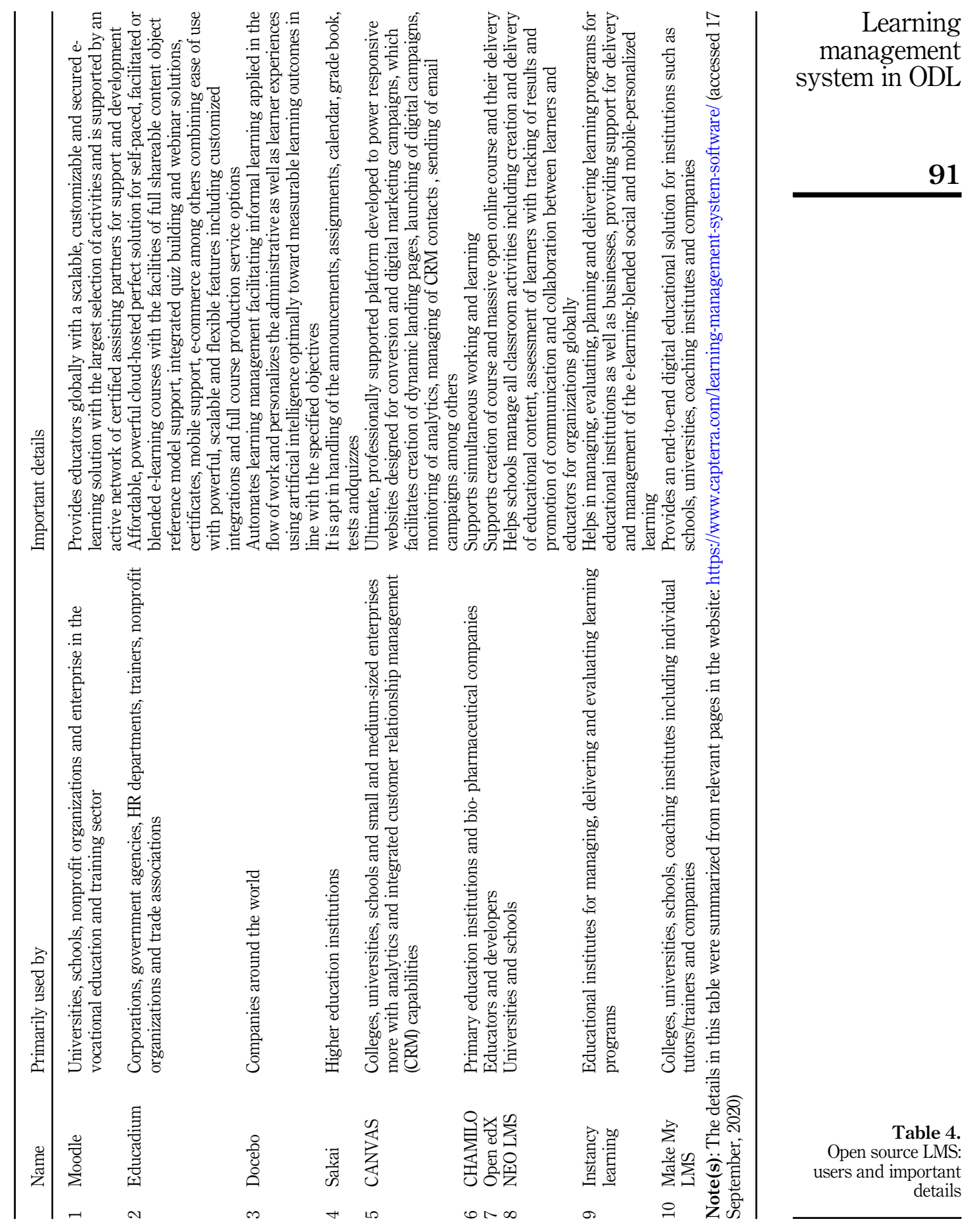


AAOUJ 16,1

preferable customizing plug-ins in addition to the facility to program new plug-ins and provide the users with the sophisticated secured internal and external communication environment comprising discussion forums, real-time chats and exchange of files and other attachments. Such OS LMSs make use of highly secured authentication tools for user access authentication in using the resources, single login authentication and message broadcasting of authentication.

The model proposed by Alameen and Dhupia (2019), based on the IEEE LTSA model demonstrating teacher-learner interaction with the system, mainly consists of learner, teacher and adaptation modules. Alameen and Dhupia (2019) highlight the model of LMS having two stores, i.e. stores of learning resources containing tutorials, tools, experiments, etc. and stores of learner records containing learners' general information along with their past details and present working behavior. Further, they inform about the presence of four processing entities, i.e. learned entity comprising individual learner or group of learners belonging to a specific category, second entity teacher and the system coach responsible for tracking their learning preference the learning material and the guidance (e.g. learning style and learning strategy), which can later be modified with the help of using LMS implementing individualized learning, the third entity delivery interacting with the system coach to get the learning resource and distribute the material to the users in the LMS and the forth entity evaluation, which undertakes learners behavior analysis and performance evaluation to be saved in the stores of learners record for future reference (Alameen and Dhupia, 2019).

Renowned researchers in the field of strategic management such as Barney (1991); Bharadwaj (2000), Peteraf $(1993)$ and Porter $(1980,1985)$ have stressed that organizations tend to achieve favorable results and ultimately competitiveness by exploiting agile execution of suitable strategy of improving efficiency and effectiveness and better utilization of resources including assets, capabilities, processes, attributes, information and knowledge primarily. Barney (2001) further emphasized the need of the possession of skills, capabilities and methods to use resources to outcompete rivals. Kant (2019) points out the need for ODL for making strategic efforts to achieve competitiveness with the optimum uses of resources, core competencies, ICT and differentiated learning experiences. Competitiveness can be attained by ODL with the help of configuration and adequate harnessing of resources helping learners get education anywhere anytime, providing them with suitable alternative of learning and securing support from advancements in the field of ICT and multimedia (Faridi and Ouseph, 2014; Kant, 2020). Therefore, OS LMS can be of great advantage for ODL facing acute competition from the growing number of institutions with similar objectives in the liberalized, privatized and globalized world (Kant, 2020).

Using appropriate LMS by an ODL institution can enhance learners' satisfaction, which can also help it in attracting more new learners. Cavanaugh (2005) rightly puts it that these satisfied learners with positive perception can help ODL institutions improve future performance achieving enhanced image of a progressive institution. COL (2020) too emphasizes that ODL institutions must make efforts for remaining connected with teachers and learners regularly with the use of advancements in technology in line with the dynamic transformations in the learning environment and opportunities. The foregoing discussions highlight that selection of an suitable OS LMS in ODL needs to be based on its efficiency in terms of enhancing the learning experience in general and e-learning experience in particular of learners and teachers both.

Karagöz et al. (2017) argue that new opportunities have been opened for ODL by the transformed technological environment. They consider LMS as the most important actor of the Internet-based ODL bringing the learners and the educators on the same platform for education and permitting them to undertake variety of educational activities such as delivery of instructional materials, assignments and evaluations. Karagöz et al. (2017) further add that 
an LMS can be used by educational institutions and other organizations for the purpose of education to learners as well as training of the employees. LMS therefore needs to be selected in line with their objectives as each of them possesses different learning processes and characteristics. Alameen and Dhupia (2019) posit that decision-makers have different priorities and thus their best choice vary depending upon the priority for license cost, flexibility, security and market share of LMS. They conclude that with the priority for license costs and flexibility, OS LMS becomes the best choice. However, with the priority for security and market share, commercial LMS becomes the best choice for the institutions. Emerging technological innovations are expected to disrupt educational environment by digitally transforming social as well as educational perspectives (Lévy et al., 2018). The shift of organizational attention in recent times toward technological innovations is emphasized by Weerawardena and Mavondo (2011). Barney (1991) and Hitt et al. (2001) argue that intangible resources are accorded higher strategic significance than tangible resources, and the LMS constitutes one such intangible resource. In these circumstances, the ODL system must explore the potentialities of OS LMS as a strategic intangible resource in its quest of competitive advantage without ignoring the associated challenges and weaknesses which could benefit one and all in the ODL system.

\section{Conclusion}

There is a need for the ODL system to adapt faster than their conventional counterparts as it serves the educational needs of more varied learners. Its huge contributions in previous five decades have been highlighted by COL (2020) in providing quality teaching-learning, harnessing optimally the basket of technological advancements which open plethora of newer possibilities if the solutions are developed by their customization according to specific contexts. OS LMS implementation can not only be cost effective if selected in ODL appropriately but can add differentiation to the system also. This study finds that the greater advantages of using the LMS by ODL institutions can offer huge advantages and benefits not only for learners and teachers but also for the ODL system by virtue of its unique features and attributes. Learners and academic counselors in ODL also have shown positive opinions as regards use of adaptive e-learning such as LMS in ODL. Using an appropriate LMS effectively and efficiently might influence the success of ODL helping it to attain sustained competitiveness in the educational market place and in strengthening the pillars of teaching-learning process by new ways of thinking to achieve high skills, GER and sustainable development goals.

This paper finds the availability of plethora of OS LMSs in the market. Selection of the best suitable LMS for any ODL institution, therefore, is a strategically crucial step, which requires perfect understanding of the features, facilities and characteristics required in line with institutional objectives. This study, on the basis of the comparison of the popular OS LMSs, demonstrates its usefulness for decision-makers in selecting the best suited LMS for ODL institutions, emphasizing that suitable OS LMS in ODL can not only be cost-effective due to OS but can also offer all the important features required for the implementation of an adaptive learning environment in ODL. With the support of appropriate OS LMS, ODL can enhance learning opportunities and experiences for its learners suffering from financial, geographical, disability, connectivity related constraints. Selecting an appropriate OS LMS can be considered to be an important significant approach in ODL as it not only can provide cost leadership but differentiate helping to achieve competitiveness. This study eliminates the disadvantages arising from the inadequacies of relevant studies explaining the strategic contributions of OS LMS in ODL. Nonetheless, the study suffered limitation that the technical details of LMS were intentionally kept simplified for easy comprehensibility for the readers with little technical background. 
AAOUJ 16,1

94

Vitso et al. (2017) argue that selection of appropriate technology is vital in attaining competitiveness and hence strategically significant. LMS, which has emerged in recent times profusely leveraging technological advancements, can revolutionize the ODL system by developing a more learner-centric ecosystem through multiple imbedded features and advantages (Kant, 2020). Selecting an appropriate OS LMS can enhance the strategic potentialities for an ODL institution. It can help the teaching-learning process in ODL in maintaining quality of the performance, which in turn can help in eliminating negative notion with respect to ODL among different stakeholders. With the unique attributes and advantages, the perfectly selected OS LMS aligned with the institutional priorities and objective can offer huge potentialities as a strategically important intangible resource for ODL. Nonetheless, in order to harness the untapped potentials and leverage the benefits of OS LMS, ODL institutions need to organize frequent trainings for stakeholders to upgrade necessary skills and improve their quality, without ignoring the importance of consistency and standards. Despite the element of cost effectiveness in the acquisition of OS LMSs, the requirement of suitably trained personnel for managing it is also emphasized in the findings. Keeping in view that use of LMS for enhancing education has continuously increased, improvement in LMSs for making them easy to use in the learning process may attract more users toward LMS in ODL. It is pertinent to mention that for ensuring its efficiency and effectiveness, appropriate system management is required for constant monitoring, updating and planning keeping in view all the technical, training, cost and learning pedagogical aspects in a holistic manner aligned with the current infrastructure, policies and teachinglearning practices. Use of OS LMS in ODL, therefore, can provide an effective and efficient learning solution containing new learning opportunities for its varied learners in the changing digital landscape of the developing countries. ODL institutions need to strategically select appropriate OS LMSs as affordable solutions for enhancing learning experiences of their varied learners, so that the LMS, as a powerful tool with wider acceptance in the educational arena, can be used for facilitating greater learning opportunities through more active collaborative interactions and participations.

\section{References}

Abdurrahman, A., Nurulsari, N., Maulina, H. and Ariyani, F. (2019), "Design and validation of inquirybased STEM learning strategy as a powerful alternative solution to facilitate gifted students facing 21st century challenging", Journal for the Education of Gifted Young, Vol. 7 March, pp. 33-56.

Alameen, A. and Dhupia, B. (2019), "Implementing adaptive e-learning conceptual Model : a survey and comparison with open source LMS", International Journal of Engineering and Technology, Vol. 14 No. 21, pp. 28-45.

Aoki, K. (2012), "Generations of distance education: technologies, pedagogies, and organizations", in Muyinda, B. (Ed.), Distance Education, IntechOpen, pp. 1183-1187.

Barney, J.B. (1991), "Firm resources and sustained competitive advantage", Journal of Management, Vol. 17 No. 1, pp. 99-120.

Barney, J.B. (2001), "Resource-based theories of competitive advantage: a ten-year retrospective on the resource-based view", Journal of Management, Vol. 27 No. 6, pp. 643-650.

Bervell, B. and Arkorful, V.(2020), "LMS-enabled blended learning utilization in distance tertiary education: establishing the relationships among facilitating conditions, voluntariness of use and use behaviour”, International Journal of Educational Technology in Higher Education, Vol. 17 No. 1, p. 6.

Bervell, B. and Umar, I.N. (2017), "A decade of LMS acceptance and adoption research in sub-Sahara African higher education: a systematic review of models, methodologies, milestones and main challenges”, Eurasia Journal of Mathematics, Science and Technology Education, Vol. 13 No. 11, pp. 7269-7286. 
Bharadwaj, A. (2000), "A resource-based perspective on information technology capability and firm performance: an empirical investigation”, Management Information Systems Quarterly, Vol. 24 No. 1, pp. 169-196.

Bordoloi, R. (2018), "Transforming and empowering higher education through open and distance learning in India", Asian Association of Open Universities Journal, Vol. 13 No. 1, p. 2018.

Brenner, S.W. (2007), Law in an Era of 'Smart' Technology, Oxford University Press, Oxford.

Brown, T.H. (2006), "Beyond constructivism: navigationism in the knowledge era", On the Horizon, Vol. 14 No. 3, pp. 108-120.

Capterra (2020), "Learning management system software", available at: https://www.capterra.com/ learning-management-system-software (accessed 17 September 2020).

Cavanaugh, C. (2005), "Distance education success factors", International Journal of Educational Telecommunication, Vol. 7 No. 1, pp. 1-6.

Cavus, N. (2015), "Distance learning and learning management systems", Procedia - Social and Behavioral Sciences, No. 191, pp. 872-877.

Cavus, N. and Zabadi, T. (2014), "A comparison of open source learning management systems , procedia - social and behavioral sciences, A comparison of open source learning management systems", Procedia - Social and Behavioral Sciences, No. 143, pp. 521-526.

Chao, R.J. and Chen, Y.H. (2009), "Evaluation of the criteria and effectiveness of distance e- learning with consistent fuzzy preference relations", Expert Systems with Applications, Vol. 36 No. 7 , pp. 10657-10662.

COL (2020), Guidelines on Distance Education during COVID-19, COL, Burnaby.

Dzandu, M.D. and Tang, Y. (2015), "Beneath a learning management system - understanding the human information interaction in information systems", Procedia Manufacturing, Vol. 3 No. 3, pp. 1946-1952.

Faridi, M.R. and Ouseph, S.N. (2014), "New directions and challenges for ODL: building collaborative business approach", European Scientific Journal, Vol. 1 Special, pp. 217-223.

Fojtik, R. (2015), "Comparison of full-time and distance learning", Procedia - Social and Behavioral Sciences, 4th World Conference on Educational Technology Researches, WCETR-2014, pp. 402-407.

Hitt, M.A., Ireland, R.D., Camp, S.M. and Sexton, D.L. (2001), "Strategic entrepreneurship: entrepreneurial strategies for wealth creation", Strategic Management Journal, Vol. 22 No. 6, pp. 479-492.

IGNOU (2011), “Expression_of_interest_for_learning_management_systems-406”, available at: http:// www.ignou.ac.in/ignou/bulletinboard/announcements/latest/detail/EXPRESSION_OF_ INTEREST_FOR_LEARNING_MANAGEMENT_SYSTEMS-406 (accessed 25 August 2020).

IGNOU (2020), IGNOU Profile 2020, Indira Gandhi National Open University, New Delhi.

Jung, I. (2005), Innovative and Good Practices of Open and Distance Learning in Asia and the Pacific (Series: APEID, UNESCO Bangkok Occasional Paper Series), International Christian University, Tokyo, Vol. 3.

Kant, N. (2019), “Competitiveness in ODL from stakeholders' perspective: a review and research agenda", Turkish Online Journal of Distance Education, Vol. 20 No. 3, pp. 59-72.

Kant, N. (2020), "Blockchain: a resource of competitive advantage in open and distance learning system", in Sharma, R.C., Yildirim, H. and Kurubacak, G. (Eds), Blockchain Technology Applications in Education, IGI Global, pp. 127-152.

Kant, N. and Anjali, K. (2020), "Traditional ecological knowledge (TEK): a resource of sustainable development for tribal communities", in Filho, W.L., Azul, A.M., Brandli, L., Salvia, A.L. and Wall, T. (Eds), Peace, Justice and Strong Institutions, Encyclopedia of the UN Sustainable Development Goals (Living Reference), Springer Nature, Switzerland AG.

Karagöz, E., Oral, L.Ö., Kaya, O.H. and Tecim, V. (2017), "LMS selection process for effective distance education system in organizations", EBEEC Conference Proceedings, The Economies of Balkan and Eastern Europe Countries in the Changed World (2016), Vol. 2017, pp. 347-356. 
AAOUJ 16,1

Lévy, W., Stumpf-Wollersheim, J. and Welpe, I.M. (2018), "Disrupting education through blockchainbased education technology", SSRN Electronic Journal. doi: 10.2139/ssrn.3210487.

Lonn, S. and Teasley, S.D. (2009), "Saving time or innovating practice: investigating perceptions and uses of learning management systems", Computers and Education, Vol. 53 No. 3, pp. 686-694.

McQuaide, S. (2009), "Making education equitable in rural China through distance learning", The International Review of Research in Open and Distributed Learning, Vol. 10 No. 1, pp. 1-21.

MHRD (2016), All India Survey on Higher Education (2015-16), MHRD, Govt. of India, Department of Higher Education, New Delhi, available at: http://mhrd.gov.in/sites/upload_files/mhrd/files/ statistics/AISHE2015-16.pdf.

Mohamedbhai, G. (2011), "Higher education in Africa: facing the challenges in the 21st century", International Higher Education, Vol. 63, pp. 20-21.

Muñoz, A., Lasheras, J., Capel, A., Cantabella, M. and Caballero, A. (2015), "On to Sakai: on the optimization of a Learning Management System using semantics and user profiling", Expert Systems with Applications, Vol. 42 Nos 15-16, pp. 5995-6007.

Naveh, G., Tubin, D. and Pliskin, N. (2012), "Student satisfaction with learning management systems: a lens of critical success factors", Technology Pedagogy and Education, Vol. 21 No. 3, pp. 337-350.

Nayak, S.R., Kant, N. and Anjali, K. (2020), "Strategy of using ICT in ODL to disseminate higher education in tribal communities: a case of MP, India", Asian Association of Open Universities Journal, Vol. 15 No. 2, doi: 10.1108/AAOUJ-05-2020-0029.

Noorani, I. (2014), "Service innovation and competitive advantage", European Journal of Business and Innovation Research, Vol. 2 No. 1, pp. 12-38.

Nunnally, J. (1978), Psychometric Theory, McGraw-Hill, New York, NY.

Peteraf, M.A. (1993), "The cornerstones of competitive advantage: a resource-based view", Strategic Management Journal, Vol. 14, pp. 179-191.

Porter, M.E. (1980), Competitive Strategy, Free Press, New York, NY.

Porter, M.E. (1985), The Competitive Advantage: Creating and Sustaining Superior Performance, Free Press, New York, NY.

Ramadhani, R., Umam, R., Abdurrahman, A. and Syazali, M. (2019), "The effect of flipped-problem based learning model integrated with LMS-google classroom for senior high school students", Journal for the Education of Gifted Young Scientists, Vol. 7 No. 2, pp. 137-158.

Shee, D.Y. and Wang, Y.S. (2008), "Multi-criteria evaluation of the web-based e- learning system: a methodology based on learner satisfaction and its applications", Computers and Education, Vol. 50 No. 3, pp. 894-905.

Siaciwena, R. and Lubinda, F. (2008), "The role of open and distance learning in the implementation of the right to education in Zambia", International Review of Research in Open and Distance Learning, Vol. 9 No. 1, pp. 149-186.

Tait, A. (2018), "Open Universities : the next phase", Asian Association of Open Universities Journal, Vol. 13 No. 1, pp. 13-23.

UNESCO (2002), Open and Distance Learning: Trends, Policy and Strategy Considerations, Division of Higher Education, UNESCO, Paris.

Ural, O. (2007), "Attidues of graduate students toward distance education, educational technologies and independent learning", Turkish Online Journal of Distance Education, Vol. 8 No. 4, pp. 34-43.

Vitso, M., Joar, B., Harkestad, G. and Krogh, S. (2017), A Study on Blockchain Technology as a Resource for Competitive Advantage (Dissertation), Norwegian University of Science and Technology, Oslo. 
Weerawardena, J. and Mavondo, F.T. (2011), "Capabilities, innovation and competitive advantage", Industrial Marketing Management, Vol. 40 No. 8, pp. 1220-1223.

Wolcott, L.L. (2003), "Dynamics of faculty participation in distance education: motivations, incentives, and rewards", in Moore, M.G. and Anderson, W.G. (Eds), Handbook of Distance Education, Lawrence Erlbaum Associates, Mahwah, New Jersey, NJ, London, pp. 549-565.

Nikhil Kant can be contacted at: Nikhilkant25apr@gmail.com

For instructions on how to order reprints of this article, please visit our website:

www.emeraldgrouppublishing.com/licensing/reprints.htm

Or contact us for further details: permissions@emeraldinsight.com 